Received Date : 22-Apr-2016

Revised Date : 10-May-2016

Accepted Date : 16-May-2016

Article type : For Debate

\title{
Surgeon-specific outcome reporting: is it time to move forward?
}

\author{
Marta PENNA ${ }^{1}$, Brendan MORAN ${ }^{2}$, Sarah CRANE $^{2}$, Roel HOMPES ${ }^{1}$, Christopher \\ CUNNINGHAM $^{1}$
}

1. Department of Colorectal Surgery, Churchill Hospital, Oxford University Hospitals, Oxford OX3 7LE, UK.

Marta Penna Colorectal research fellow

Roel Hompes Consultant Colorectal Surgeon

Christopher Cunningham Consultant Colorectal Surgeon

2. Pelican Cancer Foundation, Registered Charity 1141911, Basingstoke

Hants RG24 9NN, UK.

Brendan Moran Consultant Colorectal Surgeon

Sarah Crane Chief Executive of Pelican Cancer Foundation.

\section{Correspondence to:}

Christopher Cunningham

Department of Colorectal Surgery, Oxford University Hospitals

Email: chriscunningham@nhs.net, Tel: 01865 235657, Fax: 01865235857

This article has been accepted for publication and undergone full peer review but has not been through the copyediting, typesetting, pagination and proofreading process, which may lead to differences between this version and the Version of Record. Please cite this article as doi: 10.1111/codi.13433

This article is protected by copyright. All rights reserved. 
KEYWORDS: Surgery, Outcome reporting, Opinions, Colorectal

\section{Introduction}

Publication of surgical activity and mortality was first introduced in the United Kingdom (UK) in 2004 for adult cardiac surgery. The Kennedy Inquiry into paediatric cardiac deaths at the Bristol Royal Infirmary [1] motivated this initiative. The Freedom of Information Act in 2005 and the Francis Report [2] which appeared in 2012 led to the NHS Commissioning Board's document "Everybody Counts" [3]. Aimed to improve surgical care and promote patient safety, these reports underlined the need for greater transparency and informed patient decision-making. They recommended the publication of surgical "activity, clinical quality measures and survival rates from national audits for every practicing consultant" in nine surgical specialties and in interventional cardiology. Adjusted 90-day mortality rates are currently available online for all colorectal cancer surgeons in England [4], but the introduction of surgeon-specific outcome data (SSD) has raised concerns, not least because of the variable quality of such data and the statistical methods employed to analyse them [5], but also over the value of these results for informing patient and clinician choice. While good evidence exists that surgeons support the publication of outcome data [6], there is a potential for this to influence a surgeon's practice adversely, for example in avoiding elective surgery for high-risk patients. Alternative reporting methods may provide a more sensitive quality assessment of treatment by reflecting the multidisciplinary approach to perioperative care rather than that provided by the individual surgeon.

\section{Survey}

In an effort to establish the impact of current SSD reporting, we conducted a survey exploring views and experiences of colorectal consultants in England (see accompanying online information). Seven hundred and ninety four surgeons from 146 Trusts for whom SSD 
results have been published were contacted through the Pelican Cancer Foundation. Of these $293(33 \%)$ responded including 263 consultants, and 30 senior colorectal trainees, through a web-based questionnaire containing 20 questions (Appendix 1).. Most (69\%) respondents had worked in a consultant post for more than five years with $62 \%$ performing 25 to 50 cancer cases annually. Almost half (49\%) agreed that publishing SSD was essential to improve the results of surgery. Despite this, over $97 \%$ of respondents had concerns about the current method of reporting.

The greatest concern expressed was that of surgeons avoiding operating on high-risk patients, even if they had potentially curable disease. Other important concerns included the publication of inaccurate data and the incorrect interpretation of results by managers and the media leading to unnecessary confusion or worse. One third (34\%) of respondents stated that SSD reporting never influenced their decision-making for high-risk patients, but one quarter had avoided operating on high-risk patients because of SSD. More than half (52\%) had witnessed this practice with surgeons operating only if the patient presented as an emergency. Inevitably this strategy will result in the patient being exposed to the increased morbidity and mortality associated with emergency surgery rather than had they been operated on electively [7].

\section{Discussion}

Some might argue that a more accurate assessment of risk might lead to a more thoughtful appraisal of the patient's interest which could include avoiding surgery in the case of severe comorbidity. While this view is obviously an essential part of medical decision taking, the focus must be on what is best for the patient without regard to any effect a decision might have on the surgeon's figures.

This article is protected by copyright. All rights reserved. 
The potentially deleterious consequences of SSD reporting on current practice certainly raise the question whether we can do better. Intra- and postoperative death is, however, very uncommon in elective colorectal surgery and this limits the value of assessing the statistical significance of one surgeon's practice. Shih et al [8] found that most surgeons do not perform enough colectomies (less than 56/year) to generate a statistically reliable surgeon-specific complication rate and concluded that underpowered results are unreliable.

In clinical practice, the consultant surgeon takes responsibility and plays a central role in the decision-making of patient care plans, monitoring their progress throughout treatment, but he or she cannot prevent most postoperative deaths as these are mostly due to patient comorbidity or lack of resources and infrastructure [9]. Reporting outcome data at individual unit level may attenuate the adverse impact of undertaking high-risk cases, sharing responsibility and encouraging institutions to focus on broadening the base of multidisciplinary care, crucial to improving a patient's chance of surviving surgery. These include thorough preoperative assessment and optimisation of the patient's general condition combined with high quality perioperative hospital care, rehabilitation and comprehensive discharge planning. The evidence has demonstrated that a collaborative approach has considerably more impact on the outcome than does that of an individual surgeon [10]. More sophisticated assessment of patient care and the outcome may be provided by replacing SSD reporting with concepts being increasingly adopted in North America including "phase of care mortality analysis' and 'failure to rescue' [9]. It may also be time to re-think the terminology of "post-operative complications" to the more forgiving "adverse events" afforded to medical and radiological interventions, as the word "complications" implies human error whereas "adverse events" appear related more to the intervention and less to the responsible clinician.

This article is protected by copyright. All rights reserved. 
The results from the present survey indicate that nearly three quarters $(71 \%)$ of participating colorectal surgeons would like to see data reported from colorectal units as a whole, rather than from individual surgeons. Failure to rescue rates and patient-reporting outcome measures (PROMS) were also regarded as important outcome assessment methods by $68 \%$. Moving forward, the aim of improving patient safety and surgical care remains the same, but the way by which this is achieved needs revising. Just as the US is moving away from SSD after acknowledging its limitations, we too need to find a more reliable and constructive method of outcome reporting that reflects the work of the whole multidisciplinary team and truly informs patients in a way, that they can easily understand.

Acknowledgement: We would like to thank the Pelican Cancer Foundation for its support in accomplishing this project, including emailing colorectal surgeons registered with the Low Rectal Cancer (LOREC) development programme. We are very grateful to those surgeons who responded to the survey.

Conflict of interest: The authors have no conflict of interest.

Financial disclosures: There are no financial disclosures.

\section{References}

1. Kennedy I. The Report of the Public Inquiry into Children's Heart Surgery at the Bristol Royal Infirmary 1984-1995, The Stationery Office, London 2001.

2. The Mid Staffordshire NHS Foundation Trust Public Inquiry http://www.midstaffspublicinquiry.com/

3. Everyone counts: Planning For Patients 2013/2014 http://www.england.nhs.ukwpcontent/uploads/2012/12/everyonecounts-planning.pdf 
4. The Association of Coloproctology of Great Britain and Ireland. Individual Surgical Outcomes for 2015. http://www.acpgbi.org.uk/surgeon-outcomes/ Date accessed: $15 / 03 / 2016$.

5. Walker K, Neuburger J, Groene O, Cromwell DA, van der Meulen J. (2013) Public reporting of surgeon outcomes: low numbers of procedures lead to false complacency. Lancet 382:1674-7.

6. The Association of Coloproctology of Great Britain and Ireland. Reporting Surgeon Specific Outcomes for Colorectal Cancer. http://www.acpgbi.org.uk/news/announcements/reporting-surgeon-specific-outcomesfor-colorectal-cancer/ Date accessed: 15/03/2015.

7. Faiz O, Warusavitarne J, Bottle A, et al. (2010) Nonelective excisional colorectal surgery in English National Health Service Trusts: a study of outcomes from Hospital Episode Statistics Data between 1996 and 2007. J Am Coll Surg 210:390-401.

8. Shih T, Cole AI, Al-Attar PM et al. (2015) Reliability of Surgeon-specific Reporting of Complications After Colectomy. Ann Surg 261:920-925

9. Westaby S, De Silva R, Petrou M, Bond S, Taggart D. (2015) Surgeon-specific mortality data disguise wider failings in delivery of safe surgical services. Eur. J. Cardiothorac. Surg. 47:341-5.

10. El Bardissi AW, Duclos A, Rawn JD, Orgill DP, Carty MJ. (2013) Cumulative team experince matters more than individual surgeon experience in cardiac surgery. J. Thorac. Cardiovasc. Surg.145:328-33.

This article is protected by copyright. All rights reserved. 
Dear Colleagues,

The year 2013 saw the first open reporting of surgeon specific outcomes in colorectal surgery in the UK. This led to numerous discussions, debates and published statements both acknowledging the potential benefits of open reporting as well as raising concerns.

But what do surgeons really think about surgeon specific outcomes reporting?

Does it influence decision-making and clinical practice?

We thank you for your time and views on this controversial and sensitive matter and invite you to complete this short questionnaire. All responses are anonymous and take less than 5 minutes. We look forward to sharing the findings of the survey with you soon.

\section{Reporting Surgeon Specific Outcomes - Better patient care or cause for concern?}

\section{Please select your grade:}

\section{Consultant}

Senior fellow (post-CCT)

Senior fellow (pre-CCT)

Training registrar

Non-training registrar

Other (please specify)

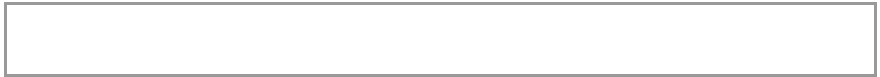

Reporting Surgeon Specific Outcomes - Better patient care or cause for concern?

\section{Please select the number of years working in a consultant post:}

$$
\begin{aligned}
& 1-3 \text { years } \\
& >3-5 \text { years } \\
& >5-10 \text { years } \\
& >10 \text { years }
\end{aligned}
$$


Reporting Surgeon Specific Outcomes - Better patient care or cause for concern?

3. For consultants: How many elective cancer cases do you perform on average per year?

$<25$

$25-50$

$51-100$

$>100$

Not applicable

\section{Reporting Surgeon Specific Outcomes - Better patient care or cause for concern?}

4. Publishing surgeon specific outcomes is an essential step towards improving surgical performance and patient outcomes.

Strongly disagree

No opinion

Strongly agree
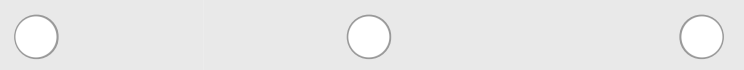

\section{Reporting Surgeon Specific Outcomes - Better patient care or cause for concern?}

5. What are your main concerns, if any, regarding surgeon specific outcomes reporting? (Please select all that apply)

Reporting of inaccurate data

Inadequate risk adjustment of results

Incorrect interpretation of results by patients leading to unnecessary confusion and concern.

Good surgeons wrongly categorised as 'poor performers' and placed under pressure by peers and managers

Surgeons avoid operating on high risk patients with potentially curable disease

Focus placed on the individual surgeon rather than the unit

No concerns regarding surgeon specific outcomes reporting.

Other (please specify) 
6. In your own practice, has the introduction of surgeon specific outcome reporting influenced your decision making for high-risk patients?

Never

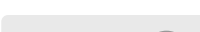

Occasionally

Frequently

\section{Reporting Surgeon Specific Outcomes - Better patient care or cause for concern?}

7. Have you ever avoided operating on a high-risk patient due to concerns over outcome reporting?

Never

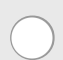

Occasionally

Frequently

\section{Reporting Surgeon Specific Outcomes - Better patient care or cause for concern?}

8. Concerns over reporting adverse outcomes, may lead to surgeons avoiding elective operations on high-risk patients, and only operate if the patient presents as an emergency.

a) Have you found this practice to exist?

Strongly disagree

No opinion

Strongly agree

Reporting Surgeon Specific Outcomes - Better patient care or cause for concern?

9. b) Do you agree with this practice?

Strongly disagree

No opinion

Strongly agree 
10. Should an alternative reporting measure of surgical outcomes be used?

Please specify which:

Data from colorectal units rather than individual surgeon

Data from UK regions including all colorectal units in that region

Reporting of failure to rescue rates

Patient-reported outcome measures (PROM)

Surgeon specific outcome reporting as currently in practice

Outcome data should not be published nationally in any form

Other (please specify)

Reporting Surgeon Specific Outcomes - Better patient care or cause for concern?

11. Are newly appointed consultants disadvantaged by surgeon outcome reporting, as the denominator of cases performed is smaller?

Strongly disagree

No opinion

Strongly agree

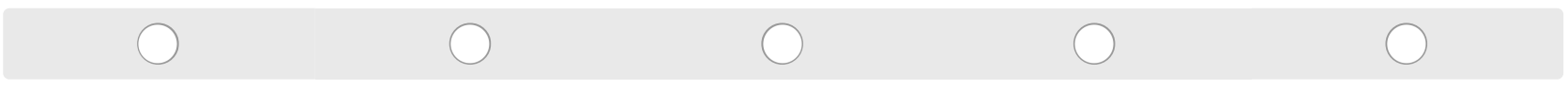

\section{Reporting Surgeon Specific Outcomes - Better patient care or cause for concern?}

12. Should reporting of surgeon specific outcome be deferred until a consultant has been in position for a specific period?

It should not be deferred

Defer by 1 year

Defer by 3 years

Defer by 5 years

Reporting Surgeon Specific Outcomes - Better patient care or cause for concern? 
13. OPTIONAL: For consultants: What was your adjusted 90-day mortality rate score on the latest results?
$0-1$
$1-3$
3-5
5-7
$>7$
Skip this question

Reporting Surgeon Specific Outcomes - Better patient care or cause for concern?

14. Any further comments:

Reporting Surgeon Specific Outcomes - Better patient care or cause for concern?

Many thanks for your valuable thoughts. We look forward to sharing the results of this survey with you soon. 